\title{
Abnormal responses of rheumatoid arthritis lymphocytes to Epstein-Barr virus infection in vitro: evidence for multiple defects
}

\author{
W L IRVING, P R WALKER, AND P M LYDYARD \\ From the Department of Immunology, Middlesex Hospital Medical School, Arthur Stanley House, 40-50 $\overrightarrow{\vec{\omega}}$ \\ Tottenham Street, London WI
}

SUMMARY Blood lymphocytes from 53 patients with rheumatoid arthritis (RA) and 44 controlși were cultured with the polyclonal B cell activator Epstein-Barr virus (EBV). Cultures supernatants were removed at weekly intervals and the amount of IgM secreted by the lymphocytes measured by an enzyme-linked immunosorbent assay (ELISA). Three majo? differences in the pattern of EBV-induced IgM synthesis by RA versus control lymphocytes were observed. Lymphocytes from RA patients, in general, produced less IgM after one week in culture than controls. In contrast, they increased their IgM secretion significantly by the end of the second week, whereas control lymphocyte cultures showed little change in IgM secretion afo this time. Control lymphocytes from EBV seropositive individuals produced undetectable amounts of IgM after five weeks in culture. However, lymphocytes from $40 \%$ of the RA patients even though they were EBV seropositive, secreted $>2000 \mathrm{ng} / \mathrm{ml}(\mu \mathrm{g} / \mathrm{l}) \mathrm{IgM}$ after five weeks The data are discussed in terms of defective B and T cell responses to EBV in lymphocytes fronक्ष patients with RA.

Key words: B lymphocytes, suppressor/cytotoxic cells.

Rheumatoid arthritis (RA) is a disease characterised by the presence of disorders in immunoregulation. ${ }^{2}$ The most striking example of this invivo is the detection of circulating antiglobulins (rheumatoid factors, RF) in the serum of $80 \%$ of RA patients, while in vitro a wide variety of experimental techniques have been used to show immunoregulatory defects in cells derived from RA patients. ${ }^{13}$

Epstein-Barr virus (EBV) is a DNA-containing virus of the herpes group. The virus specifically infects human B lymphocytes, and infection is followed by a polyclonal activation of these cells. ${ }^{4}$ These properties make EBV a useful laboratory tool for dissecting various aspects of in-vitro immunoregulation.

The presence of an abnormal immune response to EBV in RA patients was first suggested by the observations of higher titres of antibodies to various

Accepted for publication 15 January 1985.

Correspondence to Dr W L Irving.
EBV-derived antigens in the serum of RA patient compared with controls. ${ }^{56}$ Subsequently many in vestigators have shown defects in the in-vitro cellular control of EBV-induced B cell activation in RA cells. ${ }^{7-12}$ However, the in-vitro control of EBV-induced B cell activation is undoubtedly com은 plex, involving such factors as susceptibility of cells to viral infection, the action of natural killee cells, the production of soluble regulatory factors and the role of functionally different $T$ cell subsets Each experimental protocol tends to highlight on particular aspect of this multifactorial regulatory system, occurring at particular times after EBए infection. We describe here an assay system deo signed specifically to monitor regulation of EBV $\Phi$ induced $B$ cell activation at several time intervals ${ }^{5}$ after viral infection. Extension of this technique to RA cells has shown several differences in the्ष patterns of response given by cells from RA patients compared with normal cells and has suggested ways of further elucidating the defects in EBV regulatio evident in RA cells. 


\section{Materials and methods}

\section{PATIENTS AND CONTROLS}

Heparinised peripheral blood was drawn from 53 patients (16 male, 37 female, mean age 58 years, range 24-79) fulfilling the American Rheumatism Association criteria for diagnosis of RA. Treatment regimens included gold injections alone (eight patients), gold injections plus non-steroidal antiinflammatory drugs (NSAIDs) (17), gold injections plus low dose prednisone (two), NSAIDs alone (13), D-penicillamine plus NSAIDs (five), azathioprine plus NSAIDs (two), chloroquine (one), prednisone plus NSAIDs (one), and unknown (two). Two patients were not receiving drugs. Laboratory personnel and patients in hospital for non-urgent surgery (hernia repair, varicose vein stripping), provided control blood; there were 22 males and 22 females with a mean age of 37 years and a range of 19-71.

\section{E B V S E R O L OG Y}

A standard indirect immunofluorescence method was used to detect IgG antibodies to the EBV viral capsid antigen (VCA) in the serum of all donors, with the P3HR-1 cell line as a source of VCApositive cells. ${ }^{13}$ Sera were tested at a $1 / 8$ dilution and a positive test taken as evidence of prior exposure to EBV (EBV seropositivity).

\section{PREPARATION OF EB V}

Infectious virus was obtained from the supernatant of the marmoset cell line, B95- $8^{14}$ (kindly provided by Professor A Rickinson, Birmingham University), and stored in aliquots at $-70^{\circ} \mathrm{C}$.

\section{LYMPHOCYTE SEPARATION}

Blood was diluted 1:1 with Hanks's balanced salt solution, and the mononuclear cells obtained by density gradient centrifugation according to Boyum, ${ }^{15}$ using Lymphopaque (Nyegaard). The cells were washed twice with RPMI 1640 containing $5 \%$ heat-inactivated fetal calf serum (HI-FCS), counted, and resuspended at $10^{9}$ cells/l in RPMI 1640 supplemented with $10 \%$ HI-FCS, $2 \mathrm{mM}$ glutamine, penicillin $\left(10^{5}\right.$ units/l), and streptomycin (100 mg/l).

\section{CE L L C U L T URE}

$1 \mathrm{ml}$ aliquots $\left(10^{6}\right.$ cells $)$ were dispensed into $5 \mathrm{ml}$ tubes (Falcon 2003). $100 \mu \mathrm{l}$ of EBV-containing B95-8 supernatant or $100 \mu$ l of supplemented RPMI 1640 were then added to each tube. At least four replicate tubes of virally infected cells were set up for each donor. Cells were cultured at $37^{\circ} \mathrm{C}$ in a $5 \%$
$\mathrm{CO}_{2}$ humidified atmosphere. At weekly intervals the tubes were centrifuged at $1500 \mathrm{rpm}$ for seven minutes at room temperature, $900 \mu$ l of supernatant was carefully removed, and the cells resuspended in $900 \mu \mathrm{l}$ of fresh supplemented RPMI 1640.

\section{Ig M A S S A Y}

The amount of IgM secreted into the culture supernatants was measured by an ELISA. MicroELISA plates (Dynatech) were coated with 200 $\mu \mathrm{l} /$ well of a $1 / 1000$ dilution of goat antihuman $\mu$ chain (Tissue Culture Services) in carbonate/bicarbonate coating buffer. The plates were incubated at $4^{\circ} \mathrm{C}$ overnight, then washed three times with phosphate-buffered saline (PBS) containing 0.05\% Tween 20 (PBS/Tween). $200 \mu$ l of a range of IgM standards or of test supernatant was added to each well. The latter were diluted in supplemented RPMI if necessary, in order that the final optical densities obtained fell on the linear part of the standard curve. The plates were incubated at $37^{\circ} \mathrm{C}$ for two hours, then washed three times as above. Finally 200 $\mu$ l of a $1 / 1000$ dilution of peroxidase conjugated rabbit antihuman $\mu$ chain (Dako) in washing buffer was added to each well. The plates were incubated for two hours at $37^{\circ} \mathrm{C}$, then washed three times as above. $200 \mu \mathrm{l}$ of a chromogenic substrate $\left(2,2^{\prime}\right.$ azino-di-(3-ethylbenzthiazoline) sulphonic acid) dissolved in citrate phosphate buffer to which hydrogen peroxide had been added was added as substrate to each well. After 10 minutes $50 \mu$ l of a $3.2 \mathrm{~g} / \mathrm{l}$ solution of sodium fluoride in distilled water was added to each well to stop the reaction. The optical density of each well was read on a Dynatech ELISA reader at $630 \mathrm{~nm}$. Comparison of the optical densities with the standard curve enabled quantification of the IgM in each test supernatant. Each supernatant was tested in duplicate wells and the mean reading taken.

\section{PROLIFERATION ASSAY}

$200 \mu \mathrm{l}$ of peripheral blood mononuclear cells (PBMC) in supplemented RPMI $\left(10^{9}\right.$ cells/l) was dispensed into microplates, and $20 \mu \mathrm{l}$ of B95-8 supernatant or $20 \mu$ l of supplemented RPMI added. The plates were incubated at $37^{\circ} \mathrm{C}$ in a $5 \% \mathrm{CO}_{2}$ humidified atmosphere. Eighteen hours before harvesting $50 \mu \mathrm{l}$ of ${ }^{125} \mathrm{I}-\mathrm{UdR}$ (uridine deoxyribose) (specific activity $10 \mathrm{mCi} / \mathrm{l}$, Amersham) was added to each well. Plates were harvested using a Titertek multichannel harvester, and the cellular radioactivity was incorporated onto glass fibre discs. The discs were counted and the results expressed as a stimulation index $(\mathrm{SI})$, where $\mathrm{SI}=\mathrm{cpm}$ cells cultured with virus/cpm cells cultured alone. 
S T A T IS T I CS

Statistical analysis was performed by the Student's $t$ test, $\chi^{2}$ analysis, and the Kolmogorov-Smirnov twosample test.

\section{Results}

AT ONE WEEK OF CULTURE

The amount of EBV-induced IgM secretion in the supernatants of lymphocytes from controls and RA patients after one week in culture was compared (Fig. 1). Overall, larger amounts of IgM were secreted by control relative to RA lymphocytes. Thirty-one out of 53 RA patients had IgM values of $0-200 \mathrm{ng} / \mathrm{ml}(\mu \mathrm{g} / \mathrm{l})$ compared with $7 / 44$ controls $(\mathrm{p}<0 \cdot 0001)$. Only $1 / 53$ RA patients had $\geqslant 1000$ $\mathrm{ng} / \mathrm{ml}$ IgM compared with $14 / 44$ controls $(\mathrm{p}<0 \cdot 0001)$. There was a significant difference between the RA patients and controls $(p<0.002)$ as determined by the two-sample KolmogorovSmirnov test.

Since gold treatment results in the suppression of lymphocyte responses to the $T$ cell dependent mitogen pokeweed mitogen (PWM), ${ }^{16}$ it seemed possible that the reduced IgM secretion by RA lymphocytes after one week of culture with EBV could also be due to this treatment. However, as seen in Table 1, when the one-week EBV-induced IgM responses of lymphocytes from 27 patients treated with gold were compared with those of 24 other patients on a variety of other treatments (including NSAIDs (13 patients), D-penicillamine plus NSAIDs (5), azathioprine plus NSAIDs (2),
Table 1 Reduced seven-day EBV-induced IgM secretion by $R A$ lymphocytes is not the result of gold treatment

\begin{tabular}{|c|c|c|c|c|}
\hline \multirow[t]{2}{*}{ Treatment } & \multicolumn{4}{|c|}{$\lg M(n g / m l)^{*}$} \\
\hline & $<200$ & $200-500$ & $500-1000$ & $\geqslant 1000$ \\
\hline Gold (27) $\dagger$ & $16 \ddagger$ & 9 & 2 & 0 \\
\hline Other (24) & 13 & 8 & 2 & 1 \\
\hline
\end{tabular}

${ }^{*} \mathrm{ng} / \mathrm{ml}=\mu \mathrm{g} / \mathrm{l}$.

†Numbers of patients receiving gold or other treatments (NSAID (13), D-pencillamine plus NSAIDs (5), azathioprine plus NSAIDs(2), chloroquine (1), prednisone plus NSAIDs (2), and no druge therapy (2)).

‡Number of patients whose lymphocytes cultured with EBV secreted IgM in the ranges shown.

chloroquine (1), prednisone plus NSAIDs (1), anfं no drug therapy (2)), no differences were seen.

AT THE SECOND WEEK OF CULTURE

The ratio of the amount of EBV-induced IgME secreted by lymphocytes at the end of the second week of culture relative to the first week is shown in Fig. 2. Whereas control lymphocytes tended to give low ratios indicating little change in IgM secretion by the second week of culture, the values obtained for the RA lymphocytes were significantly skewe towards higher ratios. Thus $15 / 32$ control cultures showed little change in EBV-induced IgM secretiong in the second week of culture compared with the first (ratios of $\leqslant 2$ ), whereas only 4/49 RA cultures behaved similarly $(p<0 \cdot 0001)$. However, in $21 / 49$ cultures from RA patients IgM values increase

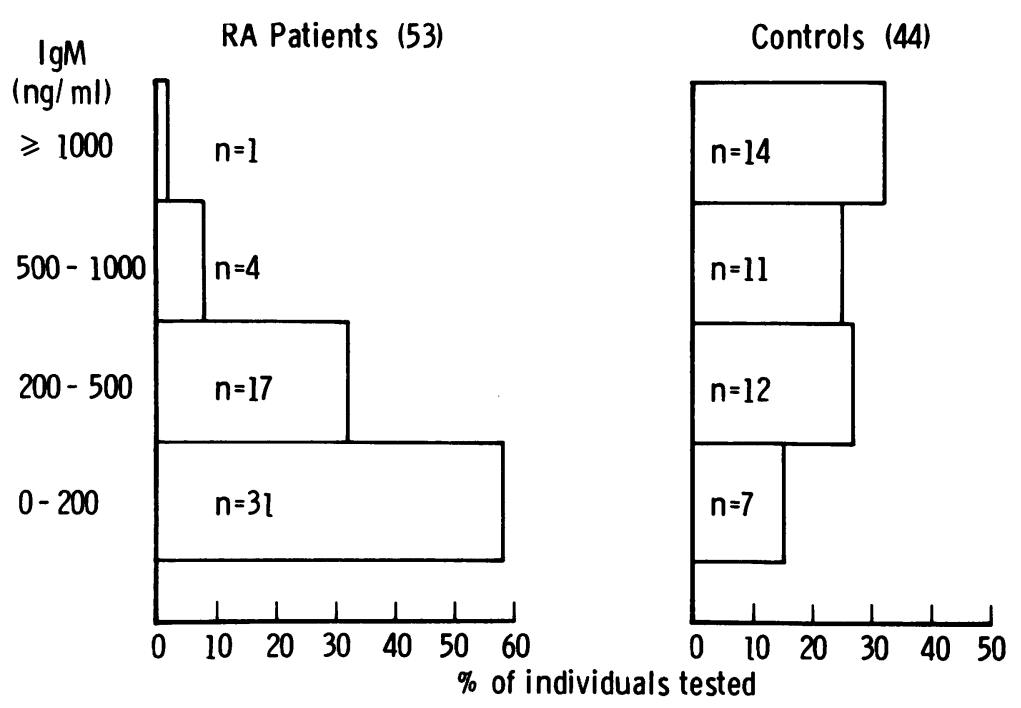

Fig. $1 E B V$-induced IgM secretion by blood lymphocytes from $R A$ patients and controls. $\mathrm{N}$ IgM was measured in the seven-day culture supernatants by an ELISA $N$ The histograms show the percentage of $R A$ and control donors whose lymphocytes secreted IgM in the ranges indicated; $(\mathrm{ng} / \mathrm{ml}=\mu \mathrm{g} / \mathrm{l})$. Figures in parentheses are the number of individuals studied. 
IgM week 2 RA Patients (49)

Controls (32)

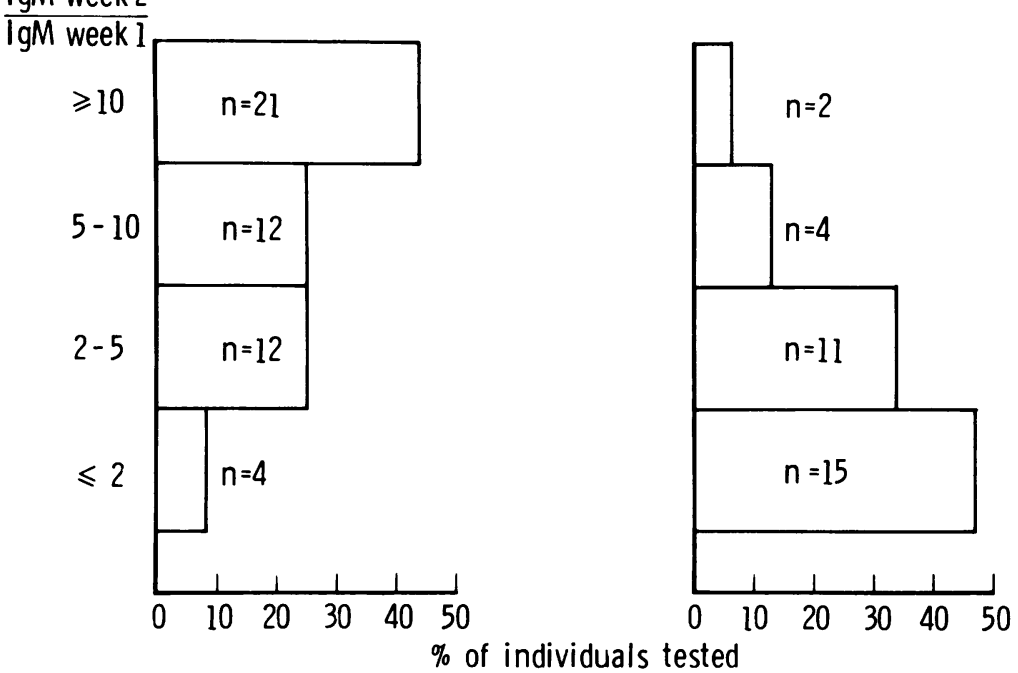

Fig. 2 Increase in EBV-induced IgM secretion by $R A$ and control lymphocytes from the first to the second week of culture. IgM was measured in the seven-day culture supernatant by an ELISA. The supernatants were removed, fresh medium added, and the IgM measured one week later. The histograms show the percentages of $R A$ and control donors with ratios of IgM secreted in the second compared with the first week indicated in the ranges shown; $(n g / m l=\mu g / l)$.

more than 10-fold during the second week compared with only $2 / 32$ controls $(p<0 \cdot 0005)$. Population analysis comparing all the RA patients with all the controls by the Kolmogorov-Smirnov test showed a significant difference $(\mathrm{p}<0 \cdot 002)$.

\section{AT THE FIFTH WEEK OF CULTURE}

EBV-infected lymphocyte cultures from 13/16 EBV seropositive control donors were secreting $<200$ $\mathrm{ng} / \mathrm{ml} \mathrm{IgM}$ by the fifth week of culture (Fig. 3). Lymphocytes from all these donors had secreted $>200 \mathrm{ng} / \mathrm{ml} \mathrm{IgM}$ in the first week of culture (data not shown), and had therefore 'switched off' their IgM secretion by the fifth week. Three out of six replicate lymphocyte cultures from a single donor (starred) were secreting $>2000 \mathrm{ng} / \mathrm{ml}$, while the other three were secreting $<200 \mathrm{ng} / \mathrm{ml}$. IgM secretion by two other control donors was very low $(<400 \mathrm{ng} / \mathrm{ml})$ and decreasing when compared with the first- and second-week data from the same individuals (data not shown).

In contrast, lymphocyte cultures from 14/38 (37\%) EBV seropositive RA patients were still secreting $>2000 \mathrm{ng} / \mathrm{ml}$ IgM by the end of week 5 and continued to develop into cell lines when transferred to Costar plates, i.e., they were behaving like the cultures from EBV seronegative control and RA donors. Nineteen out of $38(50 \%)$ of the RA patients had 'switched off' their IgM secretion by week $5(<200 \mathrm{ng} / \mathrm{ml})$, while cultures from one donor were secreting measurable but low values. Cultures from four other donors showed some

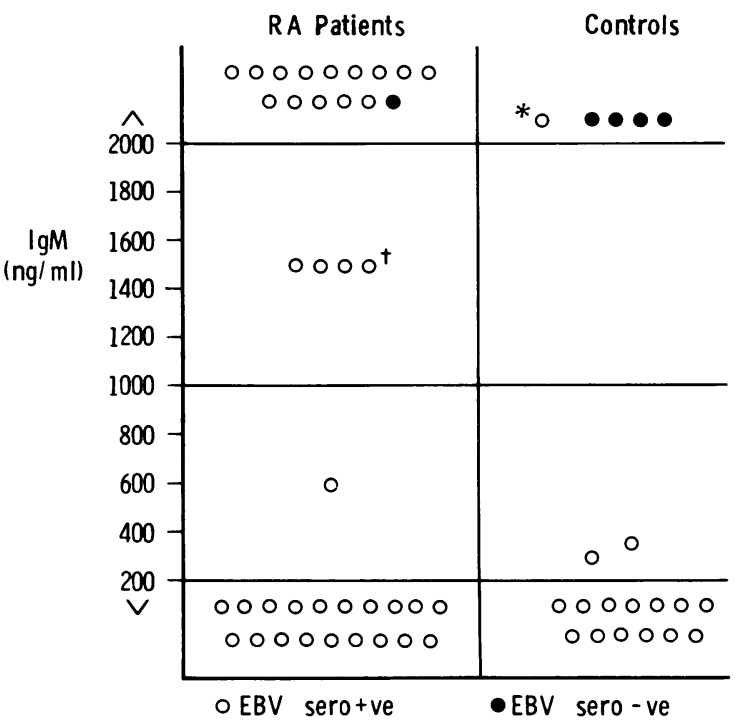

Fig. 3 Failure of $T$ cells from some EBV seropositive $R A$ patients to terminate $E B V$-induced IgM secretion after five weeks of culture. Culture supernatants were replaced at weekly intervals, and IgM measured in the fifth-week supernatant. Each symbol represents an individual $E B V$ seropositive or seronegative $R A$ patient or control. Fourteen out of $38 \mathrm{EBV}$ seropositive patients had IgM values of $>2000 \mathrm{ng} / \mathrm{ml}$. Cultures from $4 / 38$ patients showed some tubes with high and some with low secreted IgM (†). Three out of six cultures from one control donor $\left({ }^{*}\right)$ secreted $>2000 \mathrm{ng} / \mathrm{ml} \mathrm{IgM}$, while the remaining three cultures from this donor secreted $<200 \mathrm{ng} / \mathrm{ml} \mathrm{IgM}$. Cultures from all EBV seronegative donors produced $>2000 \mathrm{ng} / \mathrm{ml} \mathrm{IgM} .(\mathrm{ng} / \mathrm{ml}=\mu \mathrm{g} / \mathrm{l})$. 
culture tubes with high and some with low IgM levels.

RELATIONSHIP BETWEEN IgM SECRETION AND ${ }^{125}$ I-UdR INCORPORATION AT ONE

WEEK OF CULTURE

Lymphocyte cultures from 14 controls and 14 RA patients were compared in terms of their EBVinduced IgM synthesis and EBV-induced proliferation as measured by ${ }^{125} \mathrm{I}-\mathrm{UdR}$ incorporation. As shown in Table 2 there was no significant difference in ${ }^{125} \mathrm{I}-\mathrm{UdR}$ incorporation by the RA lymphocytes as measured by the stimulation index compared with the controls $(p>0 \cdot 6)$. However, the RA cultures secreted significantly lower amounts of IgM than the controls, with $6 / 14$ secreting $<200 \mathrm{ng} / \mathrm{ml}$ IgM compared with $0 / 14$ controls $(0.01<p<0.025)$.

\section{Discussion}

The patterns of EBV-induced IgM secretion in vitro by lymphocytes from RA patients and controls differ in three major ways. Firstly, RA peripheral blood mononuclear cells (PBMC) secrete significantly lower amounts of IgM in the first week of culture than do normal cells. Secondly, the synthesis of IgM by RA cells is markedly increased during the second week of culture, while that of control cells is only moderately increased if at all. Finally, cells from a significant proportion of EBV seropositive RA donors continue to secrete large amounts of IgM after five weeks of culture, whereas cultures from EBV seropositive control donors almost invariably fail to produce detectable amounts of IgM at this stage.

The differences in IgM secretion reported in this study are in contrast to the data of Slaughter et al. ${ }^{17}$ who found no changes in IgM production by RA compared with normal lymphocytes up to three weeks in culture. The reasons for this discrepancy are unclear, but the latter authors studied many fewer RA patients and used culture conditions $\frac{}{\varphi}$. different from those described in this study.

The defects in EBV handling by RA lymphocytes $\overrightarrow{\vec{F}}$ could be a consequence of the disease activity or drug treatments, or both. Although we did not $\frac{\bar{O}}{-}$ assess the disease activity in all patients, there $\frac{\overline{\bar{p}}}{\bar{\alpha}}$ appeared to be no relationship between disease $\Phi$ activity in 12 patients and the pattern of response to EBV. It has previously been shown that gold ${ }^{\text {s }}$ treatment in vivo inhibits PWM induced differentia-. tion of lymphocytes in vitro. ${ }^{16}$ Since many of the $\overrightarrow{\vec{\omega}}$ patients in this study were treated with gold, it $\stackrel{\omega}{\mathcal{L}}$ seemed possible that this could contribute to the

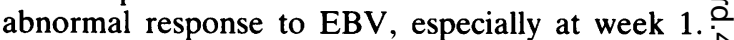
However, comparison of gold versus non-gold + patients showed no differences in the pattern of IgM ${ }_{A}^{-}$ synthesis during the first week of culture with EBV.

The reduced synthesis of IgM in the first week of $\circ$ culture by RA PBMC is unlikely to be due to fewer? $B$ cells in their lymphocyte populations, since we and others have shown that both the total number and percentage of circulating B cells in RA patients $\vec{\oplus}$ are not significantly different from those of controls. ${ }^{1819}$ There is evidence for heterogeneity in responsiveness to EBV within the normal $\mathrm{B}$ cello population. ${ }^{20-23}$ Our observation that EBV-induced proliferation in RA lymphocytes is similar to controlo lymphocytes at seven days is consistent with the premise that EBV-induced proliferation and EBV- $\cong$ induced differentiation are two independent pro- $\overrightarrow{\overrightarrow{0}}$ cesses and leads us to suggest that RA cells may be deficient in that population of $B$ cells which responds to EBV by IgM secretion. This, in turn, could be a consequence of the increased numbers of activated $B$ cells in the circulation of $R_{-}^{\text {? }}$ patients, ${ }^{19} 25$ as cells already activated respond 3 . poorly to EBV. ${ }^{24}$ Even though RA lymphocytes may contain fewer EBV-inducible IgM precursor $B \frac{\rho}{3}$ cells, they must be relatively rich in IgM $\mathrm{RF}_{\mathrm{O}}$ precursors, since there is a high spontaneous and EBV-driven production of IgM RF by RA lymphocytes in vitro. ${ }^{17}$

Table 2 Comparison of EBV-induced IgM secretion and ${ }^{125} I-U d R$ incorporation by $R A$ and control lymphocytes after one week of culture

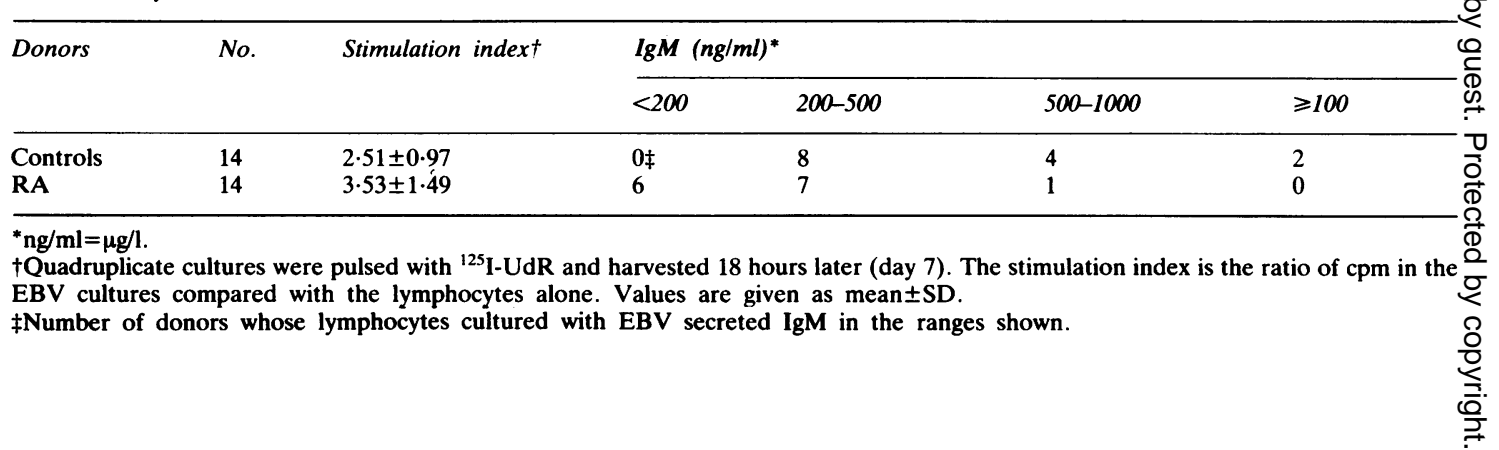


PBMC from normal donors secrete roughly similar or moderately increased amounts of IgM during the second week of culture. Cultures of control lymphocytes depleted of $\mathrm{T}$ cells markedly increase their IgM secretion during the second week of culture (data not shown), suggesting that $T$ cells regulate this response. It is therefore likely that the dramatic increase in IgM secretion between weeks 1 and 2 of culture of RA cells reflects a defect in T suppressor $\left(T_{s}\right)$ mechanism(s). This would be consistent with the work of Tosato et al. ${ }^{10}$ who used a similar assay. The suppression of EBV-induced IgM secretion may be mediated by the interferons, ${ }^{26} 27$ and in this regard, $\gamma$-interferon production by RA cells in an autologous mixed lymphocyte reaction has been reported to be decreased compared with normal cells. ${ }^{28}$

The third abnormality in the pattern of response of RA cells to EBV, that of failure to switch off IgM synthesis after five weeks in culture, is the most specific defect, since it was seen in only one of the control donors and then not in all replicate cultures. EBV-specific cytotoxic $T$ cells $\left(T_{c}\right.$ cells) develop in in-vitro PBMC cultures from normal EBV seropositive individuals, and these cells mediate regression of proliferating EBV-infected autologous $\mathrm{B}$ cells. ${ }^{28}$ Thus it is likely that these are absent or fail to expand adequately in cultures of lymphocytes from some RA patients. Indeed, defective EBV-specific $T_{c}$ function in RA, as measured by regression of long-term cultures, has also been reported by other investigators. ${ }^{1129}$ The process of generation of specific $T_{c}$ is both interleukin-1 (IL-1) and -2 (IL-2) dependent. ${ }^{30}$ Impairment of this process in cells from some RA patients may thus be due to an inability to generate or respond to IL-1 or IL-2. Interestingly other workers by different experimental protocols have reported defective production of IL-2 by PBMC from RA patients. ${ }^{31}$

The possible relationship between the putative $T_{s}$ and $T_{c}$ cell defects in RA cells described above is unclear. It is worth noting that whereas the majority of RA patients showed the putative $\mathrm{T}_{\mathrm{s}}$ defect at two weeks, only lymphocytes from $39 \%$ of them failed to switch off IgM secretion after five weeks, i.e., showed evidence of a putative $T_{c}$ defect. However, this does not formally prove that $T_{s}$ and $T_{c}$ functions are mediated by independent $T$ cell subpopulations, since the first defect may reflect low numbers of EBV-specific $T_{s / c}$ precursors, which nevertheless can expand sufficiently to mediate regression by five weeks in culture in some RA patients but not in others. In a small number of patients the degree of expansion may be critical, thus explaining why regression can occur in some replicate cultures but not in others.
We would like to thank Drs Colaco, Shipley, and Corbett for allowing us to study their patients, and Professor I M Roitt for discussions and criticisms. This work was supported by the Wellcome Trust. WLI and PML are supported by the Medical Research Council.

\section{References}

1 Roitt I M, Hay F C, Nineham L J, Male D. K. Rheumatoid arthritis. In: Lachmann P, Peters D K, eds. Clinical aspects of immunology. Oxford: Blackwell, 1982; 2: 1161-95.

2 Lydyard P M, Irving W L. Immunological aspects of rheumatoid arthritis. In: Saunders K B, ed. Advanced medicine. London: Pitman Medical, 1983; 19: 156-65.

3 Irving W L, Lydyard P M. Disordered immunoregulation in rheumatoid arthritis. In: Decker J, Scott T, eds. Rheumatology. London: Current Medical Literature, in press.

4 Rosen A, Gergely P, Jondal M, Klein G, Britton S. Polyclonal immunoglobulin production after Epstein-Barr virus infection of human lymphocytes in vitro. Nature 1977; 267: 1429-34.

5 Alspaugh M A, Tan E M. Serum antibody in rheumatoid arthritis reactive with a cell associated antigen: demonstration by precipitation and immunofluorescence. Arthritis Rheum 1976; 19: 711-9.

6 Catalano M A, Carson D A, Slovin S F, Richman D D, Vaughan $\mathrm{J}$ H. Antibodies to Epstein-Barr virus antigens in normal subjects and in patients with seropositive rheumatoid arthritis. Proc Natl Acad Sci USA 1979; 76: 5825-8.

7 Bardwick P A, Bluestein H G, Zvaifler N J, Depper J M, Seegmiller J E. Altered regulation of Epstein-Barr virus induced lymphoblast proliferation in rheumatoid arthritis lymphoid cells. Arthritis Rheum 1980; 23: 626-32.

8 Depper J M, Bluestein H G, Zvaifler N J. Impaired regulation of Epstein-Barr virus-induced lymphocyte proliferation in rheumatoid arthritis is due to a T cell defect. J Immunol 1981; 127: $1899-902$.

9 Steirle H E, Brown K A, Perry J D, Holborow E J. Abnormal responsiveness of rheumatoid $B$ cells to Epstein-Barr virus infection in vitro. Lancet 1981; ii: 1347.

10 Tosato G, Stęinberg A D, Blaese R M. Defective Epstein-Barr virus-specific suppressor T-cell function in rheumatoid arthritis. $N$ Engl J Med 1981; 305: 1238-43.

11 Gaston J S H, Rickinson A B, Epstein M A. Epstein-Barr virus-specific cytotoxic $T$ cell responses in rheumatoid arthritis patients. Rheumatol Int 1982; 2: 155-9.

12 Irving W L, Walker P R, Lydyard P M, Roitt I M. Defective rheumatoid lymphocyte function assessed by Epstein-Barr virus infection in vitro. Lancet 1982; ii: 1337.

13 Henle W, Henle G E, Horwitz C A. Epstein-Barr virus specific diagnostic tests in infectious mononucleosis. Hum Pathol 1974; 5: 551-4.

14 Miller G, Lipman M. Release of infectious Epstein-Barr virus by transformed marmoset leukocytes. Proc Natl Acad Sci USA 1973; 70: 190-3.

15 Boyum A. Isolation of mononuclear cells and granulocytes from human blood. Scand J Clin Lab Invest 1968; 21 (suppl): 77-9.

16 Olsen N, Ziff M, Jasin H E. Cellular mechanisms responsible for decreased pokeweed mitogen induced $\mathrm{B}$ cells responses in rheumatoid arthritis patients treated with gold sodium thiomalate or penicillamine. Arthritis Rheum 1983; 26 (suppl): abstract 9, S10.

17 Slaughter L, Carson D A, Jensen F C, Holbrook T L, Vaughan $J \mathbf{H}$. In vitro effects of Epstein-Barr virus on peripheral blood mononuclear cells from patients with rheumatoid arthritis and normal subject. J Exp Med 1978; 148: 1429-34.

18 Vernon-Roberts B, Currey H L F, Perrin J. T and B cells in the blood and synovial fluid of rheumatoid arthritis. Ann Rheum Dis 1974; 33: 430-5. 
19 Youinou P Y, Irving W L, Shipley M, Hayes J, Lydyard P M. Evidence for $B$ cells activation in patients with active rheumatoid arthritis. Clin Exp Immunol 1984; 55: 91-8.

20 Bird A G, Britton S, Ernbeerg I, Nilsson K. Characteristics of Epstein-Barr virus activation of human B lymphocytes. $J$ Exp Med 1981; 154: 832-9.

21 Henderson E, Miller G, Robinson J, Heston L. Efficiency of transformation of lymphocytes by Epstein-Barr virus. Virology 1977; 76: 152-6.

22 Martinez-Maza $O$, Britton S. Frequencies of the separate human B cell subsets activatable to immunoglobulin secretion by Epstein-Barr virus and pokeweed mitogen. J Exp Med 1983; 157: 1808-14.

23 Yarchoan R, Tosato G, Blaese R M, Simon R M, Nelson D L Limiting dilution analysis of Epstein-Barr virus-induced immunoglobulin production by human B cells. $J$ Exp Med 1983; 157: 1-14.

24 Aman P, Ehlin-Henriksson B, Klein G. Epstein-Barr virus susceptibility of normal human B lymphocyte populations. $J$ Exp Med 1984; 159: 208-20.

25 Papadimitriou G M, Bacon P A, Hall N D. Circulating activated lymphocytes in rheumatoid arthritis; a marker of synovial inflammation. $J$ Rheumatol 1982; 9: 217-23.
26 Thorley-Lawson D A. The transformation of adult but not human newborn lymphocytes by Epstein-Barr virus and phyto-? haemagglutinin is inhibited by interferon: the early suppression $\vec{F}$ by $\mathrm{T}$ cells of Epstein-Barr virus infection is mediated by interferon. J Immunol 1981; 126: 829-33.

27 Hasler F, Bluestein G H, Zvaifler N J, Epstein L B. Analysis of the defects responsible for the impaired regulation of Epstein- $\bar{C}$ Barr virus-induced $B$ cell proliferation by rheumatoid arthritis $\vec{乛}$ lymphocytes. I. Diminished $\gamma$-interferon production in response $\underset{\varrho}{\mathbb{D}}$ to autologous stimulation. J Exp Med 1983; 157: 173-88.

28 Moss D J, Rickinson A B, Pope J H. Long-term T-cell ${ }^{\text {C }}$ mediated immunity to Epstein-Barr virus in man. I. Complete $\vec{\circ}$ regression of virus-induced transformation in cultures of seropositive donor leukocytes. Int J Cancer 1978; 22: 662-8.

29 Pereira R S, Gear A J, Dore C J, Webster D B. Effects of cyclosporin $A$ on immunoglobulin production by $E B$ virus stimulated lymphocytes. Clin Exp Immunol 1983; 53: 115-21. 을

30 Wagner H, Hardt C, Rollinghoff M, Pfizenmaiess K, Solbach + W. T-T cell interactions in murine cytotoxic $T$ cell response. The interleukin concept. Z Immunitaetsforsch Immunobiol 1981; 159: 183-8.

31 Emery P, Panayi G S, Nouri A M E. Interleukin-2 reverses $N$ deficient cell-mediated immune responses in rheumatoid arthri-윽 tis. Clin Exp Immunol 1984; 57: 123-9. 